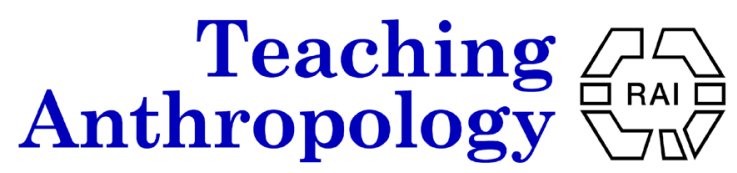

2021, Vol. 10, No. 4, pp. 84-91

\section{Reflections on East and West: Anthropology, Decolonization, and Teaching}

\author{
Shukti Chaudhuri-Brill ${ }^{1}$ \\ ${ }^{1}$ New York University/Paris, France
}

\begin{abstract}
I examine here the role of anthropology in decolonizing narratives of personal identity, taking my own story as an example. I reflect on different aspects of decolonization between east and west: that of racialized identities in different national contexts; of disciplinary contrasts between European and American anthropology; and between that of eastern and western Europe. Drawing on Ingold's notion of commoning, I discuss decolonizing practices through teaching anthropologically, using narrative as a method.
\end{abstract}

Keywords: commoning, decolonizing, identity, narrative, pedagogy

\section{Introduction}

Telling stories is one attribute we may lay claim to as a true human universal, as all peoples across time and space interpret the world and their place within it through the narratives they create. As anthropologists we spend much of our time listening to these stories, whether in the form of myth or history or as personal life stories of our interlocutors, and we, too, engage in acts of meaning-making through analysis, interpretation, and the writing of ethnography (Bruner, 1997; Behar, 2003; Stoller, 2007). Faced here with the task of reflecting on the relationship between the teaching of anthropology and processes of decolonization, I take an ethnographic approach to my own life, seeking to understand my role within a narrative of personal identity construction that takes place in a global context of colonial histories, diaspora and contemporary reckonings with the past ${ }^{1}$. My first encounter with anthropology took place in a different time and space, when the disciplinary narrative was less of decolonization and more about understanding the postcolonial order; now, as I seek to understand my place within the discipline, I find myself at times struggling to reconcile this evolving narrative with an understanding of my own colonized and decolonizing self. My personal story is punctuated by moments of pivotal significance that have guided the trajectory of my development as both scholar and educator. I describe here three such moments in the form of narrative vignettes, that may interest others who are also engaged in spinning such "webs of significance" of their own (Geertz, 1973, p. 5).

An American-trained anthropologist of color, coming from an immigrant background in the U.S and now myself an immigrant in Europe, my story is entwined with broader questions of decolonization that permeate anthropology as a discipline: as an Indian-American, with a post-colonial family heritage of displacement and loss, the trauma of which continues into the present generation; as an anthropologist, specializing on race and identity among Roma in post-communist eastern Europe; and currently as a teacher of anthropology, language, and linguistics in France, at a moment when she is coming to terms with decolonization in the context of public debates about race, religion, and national identity. In this latter capacity, I also reflect on my position within the framework of professional precarity

\footnotetext{
${ }^{1}$ A turn toward reflexivity in writing ethnography has led many anthropologists, especially those of color or who come from otherwise marginalized positions, to examine their own positionality vis-à-vis their interlocuters and the fieldwork context: for example, Jacobs-Huey (2002), Narayan (1993) and Kubica (2016) have written on the positionality of the native anthropologist, studying his/her own community; and others, writing from the perspective of feminist or queer studies, have interrogated the intersection of race, sexuality, gender, class and other identities with colonial structures of power within and without the discipline: see Adjepong (2019); others have used queer theory and the concept of critical whiteness to reflect critically upon their 'outsider' position with respect to the communities they study (Fremlová, 2018).
} 
that affects scholars across the discipline. Underlying these ruminations is a concern with fundamental questions of what it means to teach anthropology or to teach anthropologically, as I am seeking to do in educational contexts outside the traditional university setting, as described below.

\section{Becoming colonized}

Before I became an anthropologist, I was a teacher, starting in public schools in the United States and then moving into the international school circuit in Europe. This experience proved foundational to shaping my views on social issues such as race, language and social class. For instance, I taught inner-city kindergartners in Milwaukee during the crack epidemic of the late 1980s. I wondered whether I was helping or hurting them by turning them into fluent German speakers after a year in my immersion-school classroom instead of addressing the desperate communication gaps they still exhibited in English. My experiences as a teacher also influenced my interest as an anthropologist in racialization and the socialization of linguistic identity, as I first became aware of the struggles of the Roma minority in Europe against cultural and linguistic repression when I taught at the International School of Prague in the early 1990s. When I returned to Prague several years later to conduct fieldwork, exploring questions of Roma linguistic and ethnic identity formation in classroom contexts, I drew on these prior experiences of having witnessed firsthand the post-revolution transition to capitalism and democracy, the subsequent dissolution of Czechoslovakia into two independent nations, and my own experiences at the time as the target of racist state policing (having frequently been mistaken as Roma myself).

Before becoming a teacher, however, I was a learner; in fact, I have never stopped being one, viewing my teaching self through a Vygotskian lens as facilitator of learning (Vygotsky, 1962), where in the process of scaffolding instruction (Bruner, 1975) I become myself a learner of teaching practices ${ }^{2}$. It is that self, which I term the teacherlearner, that I am most concerned with reflecting on here. Before having reached that status, however, which comes with age and experience, I was simply a learner, experiencing the world and becoming socialized to my position in it as a brown-skinned little girl; growing up at first in the heady days of newly post-colonial (but not yet postapartheid) southern Africa and then thrown into middle school and high school in the (just barely) post-Civil Rights American South of the mid 1970s and 1980s. One moment from my childhood stands out as emblematic of my first encounter with the pernicious legacy of racist colonial policies:

\section{Vignette 1}

It is 1975 and I am nine years old, in fifth grade at the International School of Lusaka. I recently transferred there, after spending several years at a local primary school where the student population was from a mix of white colonial British families, staying on post-independence; local Zambians; and children from the large Indian expatriate community. In contrast, the international school caters primarily to American and European families on short-term contracts and a few children from wealthy Zambian or other African families. I had many friends in my previous school but have struggled to fit in to the new group, where I am the only brown skinned girl in my class. My nemesis takes the form of Melanie, a white South African, with a magnetic personality that draws many of the other girls into her circle, leaving me even more isolated, since she frequently cuts me out. Midway through the year, a new student joins our class, a black South African girl named Rejoice. As I write about this now, some forty years later, the irony of those names reveals itself, one of those moments of striking symbolism that seem designed by the hand of some unseen author, but which sometimes appears in the pages of real life. Rejoice is a lovely, tall and exuberant girl. She is seated at the empty desk next to mine and quickly we become friends, working together on group assignments or science experiments and sharing snacks at recess.

The crisis comes during one such break, when the other girls are gathered in a small group around Melanie, playing some game, and giggling. I wander over to join them, confident in my new-found sense of self now that I, too, have a best friend, and I beckon to Rejoice to join us. But Melanie throws us a look of disdain and walks off with her entourage, saying to me only, "if you keep being friends with her, you'll never be able to play with us". Decades later

\footnotetext{
${ }^{2}$ Bruner, of course, was using this term in the context of teaching young children, particularly through the scaffolding of adult-child discourse. I do not mean to suggest that an identical process takes place when teaching university students or adults, who are at a different cognitive level than early language learners. Nevertheless, I find the metaphor useful when I envisage my role within the learning context, since it is still essential in any teaching situation to consider how the structure of discourse between instructor and learner serves to accomplish the learning goal.
} 
the pain of that moment haunts me, as does the shame of my reaction: how I wish I could say that at that moment I chose the path of righteousness and cast my lot with Rejoice; but I was weak. I chose instead to spurn my friend, clinging to the hope that that act of betrayal would gain me acceptance in a group where, even then, I knew I would forever be condemned to the margins by the amount of melanin in my skin.

This first visceral realization of my colonized body was soon corroborated by encountering more blatant othering processes, when a year later I moved to the American South. The most literal of these took place in the context of filling out school forms that asked me to label myself racially. At the time, there existed only three possible categories: White, Black and Other; thus, my earliest sense of self as an American (even though I was a citizen, having been born there to my graduate-school parents) is that of a liminal state of not quite belonging. Later, when I was at university, my options would expand to the category of Asian

American/Pacific Islander, a group with which I identified even less. So for many years I continued to label myself as Other. Only much later, after I had reached adulthood and had been living and working outside of the U.S. where my Otherness took on different forms in differently racialized contexts, did I discover a new available category, that of South Asian or Indian American. Though I avail myself of this label, it is an identity I inhabit uneasily; like wearing a second-hand garment cast off from those of more recent generations, whose parents emigrated from an India already far enough away from its colonial past that it no longer has the same resonance for them, and who have grown up in the security of an America in which a hyphenated identity no longer seems freakish.

Reflecting on these formative experiences I cannot forget that underlying all of them are even deeper layers of history and memory that come to me from my parents - subjects of empire in their childhood and proud witnesses to the birth of a new nation, yet themselves victims of lost pride and heritage as a consequence of boundaries and new borders that were drawn in the wake of the departing rulers. Part of a first generation of seekers of a new immigrant destiny in the new world, they were then relegated to the margins of that world, conceived in shades of black and white, and their immigrant experience was overshadowed by professional and personal humiliations they never encountered under the British. My childhood memories are tinged, therefore, with an ambivalence toward their colonial past: our jubilant community celebrations of Indian independence and republic days, contrasted with my parents' proud associations with Empire, especially when contrasted with the boorish American. My father, for example, would proudly claim to be a speaker of 'the King's English', perhaps as a response to the frequent assumption, especially in 1970s Tennessee, that being non-white automatically equated to an inability to speak English.

\section{Becoming decolonized}

Out of these inchoate self-imaginings came reflexivity and self-awareness through my first encounter with anthropology when I was an undergraduate. Beginning a long, perhaps still continuing, process of decolonizing myself, I came to recognize that my personal story — individual, local and contingent - is deeply tied to a larger narrative that incorporates global structures of power and dominion. I learned to recognize in myself the double consciousness of which Du Bois (1994) speaks in the African American context, though perhaps more as a triple consciousness of my Otherness within the duality of American race relations; and that, too, multiply refracted through the prisms of race, language, religion, gender, and nationality, as I moved from the new world back to the old and there encountered other ideologies of categorization and belonging.

Anthropology furnished me with the tools to think critically about myself and to question the narrative framework through which I had been taught history and my place within it, not least through the critique and work of subaltern and postcolonial scholars. For this I was, and am, thankful. Coming to the discipline via American anthropology, with its emphasis on Boasian cultural relativism, the legacy of her colonial roots seemed less cumbrous, whereas the unique contribution made by the Boasians to dismantle racist thinking in the American context (King, 2020; Glazier, 2021) resonated with my own racialized experience, providing a welcome counterpoint. For a young woman of color entering the discipline when I did, after suffering years of being made to feel less than normal, a discipline which argued for the psychic unity of all peoples (Boas, 1901) was a welcoming place, and arguably further fueled my interest in language and cognition. The four-field focus of American 
anthropology then allowed me to pursue these interests in graduate school with a specialization in linguistic anthropology.

More recently, the Boasian legacy has been revealed to be more troubled, particularly with respect to relationships between the early anthropologists and Indigenous communities (Gomez, 2021). This is an aspect on which I continue to educate myself and to grapple with in the context of my personal orientations to the discipline. Before the emergence of current debates, however, my American naïveté had already been tested, far more directly, as I was confronted with having to justify myself as an anthropologist in the eastern European context where I did my fieldwork.

\section{Vignette 2}

It is 2002 and I am conducting fieldwork in Prague in an adult education classroom for Roma who are seeking a high-school diploma. The students span all generations, from a 75-year-old woman to those in their early twenties. We have been talking about race and integration in the U.S., and about my experiences there and in the Czech Republic, as someone who looks like them but who has the advantage of holding an American passport. They ask me many questions about civil rights and the heritage of Martin Luther King, Jr., whom many have learned about through their education program and from watching television. I have tried (imperfectly) to explain to them what it is I do as an anthropologist, and why I am spending time with them here.

The conversation turns to a discussion of whether or not I am what they call a coconut: someone who is brown on the outside but white inside. The debate becomes quite heated, with two opposing camps forming: those who say my experience on the receiving end of discrimination and racism aligns me with them, and those who argue that the vastly different American context precludes my capacity to understand what it means to be Roma in Europe. To my chagrin, the argument is clinched in favor of the latter camp, when one of the most respected members of the class, a former champion boxer, rises to present his verdict: the fact that I am there as an anthropologist means that no matter how 'black'3 I am on the outside, I cannot be other than a coconut; only a 'white' person could seek such an identity in the first place.

Through this encounter I became aware of the deep-seated mistrust held by Roma toward social scientists, a skepticism that could not easily be overcome, despite initial feelings of comradeship based on a perceived shared history ${ }^{4}$. Indeed, why should a common phenotype make up for our vastly different experiences, wrought over almost a millennium across three continents; differences not only of caste and class, but of different colonial encounters and forms of subjugation? I realized that some confusion about my intentions was created through slips of language and translation, but that, in general, my identity as an anthropologist marked me as complicit in the creation of a problematic narrative of the Roma people, a narrative that has repeatedly led to their marginalization, social and economic deprivation, and to genocide. After all, the Nazi anthropologists who provided the rationale for sending the Roma to the camps had drawn from American concepts of race in developing their theories (Schafft, 2002). In the face of such ambivalent reactions from my Roma interlocutors, I began to enter into a more uneasy relationship with my anthropologist self, for the first time feeling challenged within a discipline that, on the one hand brought me such personal empowerment, but on the other hand seemed to have been complicit in bringing such misery upon the very people with whom I now hoped to collaborate.

Further, decolonization takes on different connotations when placed in the context of east-west relations and that of a former Soviet satellite state, as I learned from the perspective of Czech interlocutors. As Shmidt and Jaworsky (2021) discuss, the racialization of Roma as 'black' and their constant depiction as 'Other' has historically been used by eastern Europeans to present themselves in contrast as white. Within a Europe of unequal political and social power, where western racial classifications were wielded not only on colonized subjects in the far-flung territories of empire but also on their central and eastern European neighbors, such claims to racial parity helped

\footnotetext{
3 The concept of 'blackness' among the Roma refers to more than skin color: it is, rather, a way of being and acting in the world, that contrasts to the gadjo, or white, worldview (Chaudhuri-Brill, 2012).

${ }^{4}$ In their studies, great weight had been laid on the Indian origins of the Roma people, as a way to generate a sense of pride in their history and identity; students had initially been excited to meet me for this reason.
} 
raise the status of eastern Europeans at the expense of the Roma. Furthermore, for Czechs, questions of decolonization that are current in the west are viewed through a different lens, where European postcolonial discourse needs to be interpreted through the parallel but distinct framework of Soviet colonization (Pucherová and Gáfrik, 2015).

My fieldwork among Czech Roma in this context left me with profound questions regarding what I thought I knew about history and colonialism, and about the place of anthropology in this context. At the time of my fieldwork, Czech anthropology was also just beginning to emerge as an independent discipline separate from Soviet-era ethnological studies (Skálnik, 2002), and my collaborations were primarily with scholars in sociology, linguistics and Romani studies departments. Later, as I was writing my dissertation, I learned about ongoing Czech anthropological research on Roma settlements in Slovakia, which left me with the troubled sense that the discipline was engaged in exacerbating racial disparities and social inequalities: the promotion of narrow theories, such as the culture of poverty argument, to explain Roma marginalization and poverty, and the exclusion and denigration of Roma voices of opposition or critique, seemed destined to increase distrust toward social science. I worried that Roma interlocutors would, with reason, refrain even more from engaging with anthropologists (Chaudhuri-Brill, 2012, pp. 143-150).

\section{Pedagogical Practice as Decolonizing Practice}

This more nuanced understanding of anthropology and of concepts such as race and identity in the European context has only been deepened by my experience of living in France for almost two decades now, a period during which racial and religious tension has grown to challenge the dominant discourse of Republicanism and racial blindness. Working collabratively with younger scholars on this special issue, I have also come to realize how my experience within the discipline has shaped me differently, leaving me critical of its history and cognizant of its many failings within the ivory tower, yet ultimately more hopeful of its value to contribute to our understanding of the human experience.

\section{Vignette 3}

It is 2011, and I am a teaching adjunct for a course on Language and Culture at a small, elite liberal arts school in Massachusetts. In my course are several Posse scholars ${ }^{5}$ from the Bronx as well as several others who are white and come from middle or upper-middle class backgrounds, many of them having studied at private schools. Class discussions are often quite lively, as students share different perspectives and background experiences. However, as we approach the first writing assignment, I begin to realize that several of the Posse students are experiencing significant stress and feeling insecure about their written performance. I am distressed when one of the papers I receive contains clearly plagiarized material. When I confront the student, it becomes clear that her fear of failing to write adequate academic English was the catalyst for her attempt to copy someone else's words. Despite departmental policy, but with the blessing of the department head, I do not fail the student; however, I am troubled by how to best help her to conquer her fear and to support her future academic progress, where her lack of linguistic capital will continue to be a disadvantage.

In the same class, another Posse student, a young woman of Dominican Republic descent, is particularly interested in posing questions and discussing topics such as the socialization of literacy. After the semester ends, I receive an email from her, thanking me for the class, and explaining that reading Bourdieu on the political economy of language had been a real revelation; that she felt incredibly liberated by now having a framework through which to understand her own sense of linguistic alienation in American society and to have the scholarly understanding through which she could now analyze and articulate her experience. I am filled with a sense of purpose and accomplishment at having reached at least one student in a way that now gives her the power to construct and control her own narrative.

5 The Posse program selects students from mainly urban minority families, first-generation college students, who attend their higher education institution with a group of students from a similar background, their 'posse', and who provide each other needed support and encouragement. https://www.possefoundation.org/about-posse 
This experience, and others like it, have served to reinforce my conviction that anthropology can be a motivator of social justice and that the teaching of it should have a more central role in the discipline. However, nowhere in my training, and I daresay this is true for most students of anthropology, was I taught to reflect on anthropology as a means of education and to think, accordingly, about best teaching practices. Influenced by Freire's (2013) concept of critical pedagogy, I seek new methods and forms through which to develop myself as an educator, both as teacher of anthropology and of language, and as an educator who teaches anthropologically. For me, this means placing the student and their life story at the center of the teaching process and creating opportunities that enable us to engage dialogically in the learning process, where the sharing of my own lived experiences can create a communal learning space. This approaches the idea of commoning, as articulated by Ingold in his recent monograph on anthropology and education: "for sharing to be educative, I have to make an imaginative effort to cast my experience in ways that can join with yours, so that we can —in a sense — travel the same paths, and in so doing, make meaning together" (Ingold, 2018, p. 4). The target student in this model is not only, then, the student of anthropology, but any individual for whom such engagement might deepen the understanding of their own life story, motivating new perspectives on their own positionality; and the contexts for such encounters reach beyond the walls of the traditional university classroom.

The distinction between the roles of anthropologist who teaches and educator who teaches anthropologically becomes pertinent as opportunities to teach traditional anthropology in university settings dwindle. Facing even fewer opportunities to enter mainstream academia once I moved to France, I have tried instead to find non-traditional contexts in which to continue to develop professionally. I have been fortunate to find a blend of teaching situations which permit me to experiment and innovate with teaching methods in contexts as varied as a major American university, various French institutions of higher education, and as a teacher of English across the spectrum, from young children to professional, working adults. What has facilitated this access to teaching opportunities is the possession of a sought-after commodity: American English. While this particular asset is not of great relevance at universities, it is greatly prized among engineering and technology schools in France. Additionally, the fact that I am a PhD- holding social scientist has led to unexpected teaching opportunities, for top tier engineering schools place high value on developing 'soft skills' of multicultural communication and international understanding among their students, many of whom go on to work at high levels in international research, business and government.

In these contexts, usually in the Department of Language and Culture rather than the social science department, I have been given the opportunity to develop 'theme' classes in anthropology and/or linguistics, taught in English. Students in these settings are often thirsty to engage with topics such as language and power, identity, decolonization, and globalization, topics which have entered the public discourse in France in the context of terrorism, debates about museum reparations and cultural heritage, and comparisons with the Black Lives Matter and other social justice movements around the world. Many students bring with them family and personal histories that intersect with these themes and, like me, bring entangled identities to multiple encounters with racialized structures of inequality. The language classroom provides a stimulating context in which to engage with these issues, to 'common', in Ingold's terms, with students who come from different backgrounds, and to think comparatively with the perspectives that I bring of the American and also the eastern European context. Although courses need to be structured very differently from the traditional university semester, and teaching time is significantly reduced, these courses provide new ways to think of teaching anthropology and of reaching a broader audience. One of the challenges faced is how to convey ideas about theory and methodology to students who may not have the same background and context of the social sciences as those at university. Another question concerns the role of reading or studying ethnography in such, more limited, contexts. As Ingold (2008) and others (e.g. Ahmad, 2021) have discussed, however, the often unquestioned equivalence between anthropology and ethnography can be interrogated. One of the most passionate discussions in which these science and engineering students like to participate revolves around questions of epistemology and the limits of different methodologies for gathering and interpreting data; ethnography can be brought into the discussion in this way, as one form of inquiry, among others. 


\section{Conclusion}

I began this article by taking an ethnographic perspective to my own life, seeking to understand my own positionality as an anthropologist by viewing my life story through a narrative lens. The use of narrative can be a powerful teaching tool as well, one that lends itself well both to teaching language and to teaching anthropologically. Presenting abstract theoretical concepts by means of storytelling is one method I am experimenting with. Using other forms of narrative to present "ethnographic" material (for example, science fiction) has been another way to engage students' interest at the conceptual level. Writing has been and continues to be an integral part of doing anthropology, yet different writing practices have evolved in tandem with evolving discourses about representation and authority within the discipline (Wulff, 2021). In this vein, I also seek to teach students to think and write ethnographically about their own lives, 'commoning' with them to find shared narrative threads and helping them weave these together within broader understandings of history and society. I hope in this way to create shared learning spaces which themselves form signifying moments in the life histories of my students.

\section{References}

Adjepong, A. (2019). Invading Ethnography: A Queer of Color Reflexive Practice. Ethnography, 20(1), 27-46.

Ahmad, I. (2021). Anthropology and Ethnography are Not Equivalent: Reorienting Anthropology for the Future. Berghahn, Oxford.

Behar, R. (2003). Ethnography and the book that was lost, Ethnography, 4(1), 15-39.

Boas, F. (1901). The Mind of Primitive Man. Science, 13(321), 281-289.

Bruner, E.M. (1997). Ethnography as Narrative. In L.P. Hinchman and S. Hinchman (Eds.), Memory, Identity and Community: the Idea of Narrative in the Human Sciences, (pp. 264-280). State University of New York Press, Albany.

Bruner, J. (1975). The Ontogenesis of Speech Acts. Journal of Child Language (2), 1-40.

Chaudhuri-Brill, S. (2012). We Are No Longer Real": Discourses of Identity and Authenticity among Czech Roma. [Unpublished doctoral dissertation]. Brandeis University.

Du Bois, W.E.B. (1994). The Souls of Black Folk. Grammercy Books, New York.

Freire, P. (2013). Education for Critical Consciousness. Bloomsbury Academic, New York.

Fremlová, L. (2018). Non-Romani Researcher Positionality and Reflexivity: Queer(y)ing One’s Own Privilege. Critical Romani Studies, 1(2), 98-123.

Geertz, C. (1973). The Interpretation of Cultures. Basic Books, Inc., New York.

Glazier, J. (2020). Anthropology and Radical Humanism. Michigan State University Press, East Lansing.

Gomez, M. (2021, January 27). UC Berkeley Removes Kroeber Hall Name, Citing Namesake’s 'Immoral' Work with Native Americans. Los Angeles Times. https:/ /www.latimes.com/california/story/2021-01-27/uc berkeley-kroeber-hall

Ingold, T. (2008). Anthropology is Not Ethnography. Proceedings of the British Academy. The British Academy, (154), 69-92.

--- (2018), Anthropology And/As Education. Routledge, London. 
Teaching Anthropology 2021, Vol. 10, No. 4, pp. 84-91

Jacobs-Huey, L. (2002). The Natives are Gazing and Talking Back: Reviewing the Problematics of Positionality, Voice, and Accountability among 'Native' Anthropologists. American Anthropologist, 104(3), 791-804.

King, C. (2020). Gods of the Upper Air. Anchor Book, New York.

Kubica, G. (2016). How “Native" is My "Native Anthropology"? Positionality and the Reception of the Anthropologist's Work in Her Own Community-A Reflexive Account. Cargo, 14(1-2), 81-99.

Narayan, K. (1993) How Native is a 'Native' Anthropologist? American Anthropologist, 95(3), 671-686.

Pucherová, D., \& Gáfrik, R. (2015). Introduction: Which Postcolonial Europe? In D. Pucherová, \& R. Gáfrik, (Eds.), Postcolonial Europe? Essays on Post-Communist Literatures and Cultures, (pp. 1- 9). Brill-Rodopi, Leiden.

Schafft, G.E. (2002). Scientific Racism in Service of the Reich: German Anthropologists in the Nazi Era. In A. E. Hinton (Ed.), Annibilating Difference: The Anthropology of Genocide, (pp. 117-136). University of California Press.

Shmidt, V., \& Jaworsky, B.N. (2021). Historicizing Roma in Central Europe: Between Critical Whiteness and Epistemic Injustice. Routledge Ltd.

Skalník, P. (2002). A Post-Communist Millenium: the Struggles for Sociocultural Anthropology in Central and Eastern Europe. Set Out, Prague.

Stoller, P. (2007). Ethnography/Memoir/Imagination/Story. Anthropology and Humanism, 32(2), 178-191.

Vygotsky, L. (1962). Thought and Language. The MIT Press, Cambridge, MA.

Wulff, H. (2021). Writing Anthropology. Cambridge Encyclopedia of Anthropology Online Database. https://www.anthroencyclopedia.com/entry/writing-anthropology

Disclosure statement: No potential conflict of interest was reported by the authors. 